\title{
LMO1 polymorphisms reduce neuroblastoma risk in Chinese children: a two-center case-control study
}

\author{
Jiao Zhang ${ }^{1, *}$, Huiran Lin ${ }^{3, *}$, Jiaxiang Wang ${ }^{1}$, Jing $\mathrm{He}^{2}$, Da Zhang ${ }^{1}$, Pan Qin ${ }^{1}$, Lin \\ Yang ${ }^{1}$ and Lizhao Yan ${ }^{1}$ \\ ${ }^{1}$ Department of Pediatric Surgery, The First Affiliated Hospital of Zhengzhou University, Zhengzhou 450052, Henan, China \\ ${ }^{2}$ Department of Pediatric Surgery, Guangzhou Institute of Pediatrics, Guangzhou Women and Children's Medical Center, \\ Guangzhou Medical University, Guangzhou 510623, Guangdong, China \\ ${ }^{3}$ Animal Experimental Management Center, Public Technology Service Platform, Shenzhen Institutes of Advanced Technology, \\ Chinese Academy of Sciences, Shenzhen 518055, Guangdong, China \\ *These authors contributed equally to this work
}

Correspondence to: Jiao Zhang, email: zhangjiaomail@126.com Jing He, email: hejing198374@gmail.com

Keywords: LMO1, neuroblastoma, GWAS, polymorphism, susceptibility

Received: June 05, 2017

Accepted: July 25, 2017

Published: August 07, 2017

Copyright: Zhang et al. This is an open-access article distributed under the terms of the Creative Commons Attribution License 3.0 (CC BY 3.0), which permits unrestricted use, distribution, and reproduction in any medium, provided the original author and source are credited.

\section{ABSTRACT}

Previous genome-wide association and validation studies suggest that LIM domain only 1 (LMO1) gene polymorphisms affect neuroblastoma susceptibility. In this work, we used Taqman methodology to genotype four LMO1 polymorphisms (rs110419 A > G, rs4758051 G > A, rs10840002 A > G and rs204938 A > G) in 118 neuroblastoma cases and 281 controls from Northern China. Odds ratios (ORs) and 95\% confidence intervals (CIs) were used to evaluate the association. We found that rs4758051 G > A was associated with a decreased neuroblastoma risk (AA vs. GG: adjusted $O R=0.28,95 \% \mathrm{CI}=0.13-0.62 ; \mathrm{AG} / \mathrm{AA}$ vs. GG: adjusted $\mathrm{OR}=0.62,95 \%$ $\mathrm{CI}=0.40-0.97$; AA vs. GG /AG: adjusted $\mathrm{OR}=0.33,95 \% \mathrm{CI}=0.15-0.69)$. Likewise, carrying the rs $10840002 \mathrm{G}$ allele was also associated with a decreased neuroblastoma risk in this Northern Chinese population. In a combination analysis using Southern and Northern Chinese populations, we found that those carrying the rs110419 G, rs4758051 A or rs $10840002 \mathrm{G}$ allele were at decreased neuroblastoma risk, and this finding was supported by a false-positive report probability analysis. These results further verify that LMO1 polymorphisms are protective against neuroblastoma. Casecontrol studies with larger samples and using other ethnicities are still needed to confirm our conclusion.

\section{INTRODUCTION}

Neuroblastoma is a common solid tumor derived from primordial sympathetic neural precursors and has complicated clinical manifestations [1]. Around the world, it ranks as the third leading cause of cancer-related death in children [2]. In China, neuroblastoma accounts for nearly $10 \%$ of childhood tumors, and its incidence is about 7.7 cases per million [3]. Despite great achievements in multimodality treatment, the 5-year survival rate for neuroblastoma remains at less than 40\% [4]. Moreover, due to their chronic health conditions, survivors have difficulty finding marriage partners and employment [5]. Thus, neuroblastoma remains a great burden for the affected children and for their families and society [6].

The etiology of neuroblastoma is not yet fully understood, and the risk factors affecting the susceptibility to neuroblastoma have not been well documented [7]. Epidemiological studies suggest children may be more susceptible to neuroblastoma if their parents were exposed to environmental risk factors, including radiation sources, wood dust and hydrocarbons [8, 9]. However, most children whose parents are exposed to environmental risk factors do not develop neuroblastoma [10]. Mounting 
evidence suggests genetic polymorphisms may somehow influence the predisposition to neuroblastoma [11-15].

The LIM domain only 1 (LMO1) gene is located on chromosome 11p15 and encodes an intertwining LIM-only transcriptional regulator [16]. LMO1 is a member of the $L M O$ gene family $[17,18]$ and is highly expressed in bone marrow and the nervous system [19], though it was first identified at human $\mathrm{T}$ cell acute lymphoblastic leukemia chromosomal translocations [20]. LMO1 protein has been implicated in the initiation and development of several cancers [18]. In addition, LMOI gene single nucleotide polymorphisms (SNPs) reportedly affect susceptibility to acute lymphoblastic leukemia [21] and neuroblastoma [16].

We previously investigated the association between $L M O 1$ polymorphisms and neuroblastoma risk in a Southern Chinese population [22]. Given the likely genetic variation across different regions, the respective roles of genetic factors in neuroblastoma risk may differ. Therefore, to further confirm the relationship between LMO1 polymorphisms and neuroblastoma risk, we performed the current hospital-based case-control study using subjects from Northern China.

\section{RESULTS}

\section{Population characteristics}

The demographic characteristics of the included 118 cases and 281 controls are summarized in Supplementary Table 1. No significant differences were observed in the age $(P=0.189)$ or gender $(P=0.196)$ distribution between cases and controls. According to the INSS criteria [23], 15 (12.82\%) patients were classified as stage I, $31(26.50 \%)$ as stage II, $19(16.24 \%)$ as stage III, $49(41.88 \%)$ as stage $\mathrm{IV}$, and $3(2.56 \%)$ as stage $4 \mathrm{~s}$ neuroblastoma. Among these, $89(75.42 \%)$ tumors originated in the adrenal gland, $19(16.10 \%)$ in the mediastinum, and $10(8.47 \%)$ and other regions.

\section{LMO1 polymorphisms and neuroblastoma risk in Northern Chinese children}

The genotype frequencies of the four LMOI polymorphisms and their associations with neuroblastoma risk are listed in Table 1. Among the controls, all four tested SNPs were in Hardy-Weinberg equilibrium (all $P_{\text {HWE }}>0.05$ ). Moreover, the analyses indicated that carrying the rs4758051 A allele had a protective effect against developing neuroblastoma (AA vs. GG: adjusted odds ratio $(\mathrm{OR})=0.28,95 \%$ confidence interval $(\mathrm{CI})=$ $0.13-0.62, P=0.002 ; \mathrm{AG} / \mathrm{AA}$ vs. GG: adjusted $\mathrm{OR}=$ $0.62,95 \% \mathrm{CI}=0.40-0.97, P=0.035$; AA vs. GG/AG: adjusted $\mathrm{OR}=0.33,95 \% \mathrm{CI}=0.15-0.69, P=0.003$ ). Similarly, we found that carrying the rs $10840002 \mathrm{G}$ allele was associated with a decreased risk of neuroblastoma (GG vs. AA: adjusted $\mathrm{OR}=0.42,95 \% \mathrm{CI}=0.21-0.85$,
$P=0.016 ; \mathrm{GG}$ vs. AG/AA: adjusted $\mathrm{OR}=0.48,95 \%$ $\mathrm{CI}=0.26-0.91, P=0.025)$. However, we failed to detect an association between the rs $110419 \mathrm{~A}>\mathrm{G}$ or $\operatorname{rs} 204938 \mathrm{~A}>\mathrm{G}$ polymorphism and neuroblastoma risk, whether or not adjusted for age and sex.

\section{LMO1 polymorphisms and neuroblastoma risk in combined subjects}

To further elucidate the association between $L M O 1$ polymorphisms and neuroblastoma risk, we combined our present results the data from our earlier study [22]. In the combination analysis (Table 2), we found that those carrying the rs $110419 \mathrm{G}$ allele were at decreased risk of neuroblastoma (AG vs. AA: adjusted $\mathrm{OR}=0.67,95 \% \mathrm{CI}$ $=0.51-0.88, P=0.004 ;$ GG vs. AA: adjusted $\mathrm{OR}=0.58$, $95 \% \mathrm{CI}=0.40-0.84, P=0.004 ; \mathrm{AG} / \mathrm{GG}$ vs. AA: adjusted $\mathrm{OR}=0.65,95 \% \mathrm{CI}=0.50-0.83, P=0.001)$, as were those carrying the rs4758051 A allele (AA vs. GG: adjusted $\mathrm{OR}=0.57,95 \% \mathrm{CI}=0.39-0.84, P=0.005$; AA vs.

GG/AG: adjusted $\mathrm{OR}=0.59,95 \% \mathrm{CI}=0.41-0.84$, $P=0.004$ ) or the rs $10840002 \mathrm{G}$ allele (GG vs. AA: adjusted $\mathrm{OR}=0.66,95 \% \mathrm{CI}=0.46-0.95, P=0.026$; $\mathrm{GG}$ vs. AG/AA: adjusted $\mathrm{OR}=0.68,95 \% \mathrm{CI}=0.49-0.94$, $P=0.020$ ). No significant association was observed between rs204938 A > G and neuroblastoma risk.

False-positive report probability (FPRP) analysis showed that all of the statistically significant associations remained noteworthy, when a prior probability of association of 0.25 was considered. At a prior probability level of 0.1 , all except one association (rs10840002 A > G) remained noteworthy. At a prior probability level of 0.01 , only the association between $\operatorname{rs} 110419 \mathrm{~A}>\mathrm{G}$ and neuroblastoma risk remained noteworthy $(\mathrm{FPRP}=0.168)$. Detailed information from the FPRP analysis is listed in Table 3.

\section{DISCUSSION}

In the present case-control study, we further verified the effect of $L M O 1$ polymorphisms on neuroblastoma risk in a Northern Chinese population. Consistent with our earlier findings [22], we observed that LMO1 polymorphisms were associated with a decreased risk of neuroblastoma. To our knowledge, this is the first study to validate the association between $L M O 1$ polymorphisms and neuroblastoma risk using two resident groups in China. This combined analysis improves the statistical power for assessing the impact of $L M O 1$ polymorphisms on neuroblastoma risk.

A previous genome-wide association study revealed that $L M O 1$ polymorphisms were associated with predisposition to neuroblastoma [16]. In that study, Wang et al. detected four SNPs in $L M O 1$ gene (rs110419 A > G, rs4758051 G > A, rs $10840002 \mathrm{~A}>\mathrm{G}$ and rs204938 A > G) that were associated with neuroblastoma risk in subjects 
Table 1: Association of $L M O 1$ polymorphisms with neuroblastoma susceptibility in children from Henan province

\begin{tabular}{|c|c|c|c|c|c|c|c|}
\hline Genotype & $\begin{array}{l}\text { Cases } \\
(N=118)\end{array}$ & $\begin{array}{l}\text { Controls } \\
(N=\mathbf{2 8 1})\end{array}$ & $P^{\mathbf{a}}$ & $\begin{array}{l}\text { Crude OR } \\
(95 \% \text { CI) }\end{array}$ & $P$ & $\begin{array}{l}\text { Adjusted OR } \\
(95 \% \text { CI })^{\mathrm{b}}\end{array}$ & $P^{\mathbf{b}}$ \\
\hline \multicolumn{8}{|c|}{ rs110419 $(\mathrm{HWE}=0.677)$} \\
\hline $\mathrm{AA}$ & $47(39.83)$ & $86(30.60)$ & & 1.00 & & 1.00 & \\
\hline $\mathrm{AG}$ & $54(45.76)$ & $142(50.53)$ & & $0.70(0.43-1.12)$ & 0.134 & $0.69(0.43-1.11)$ & 0.122 \\
\hline GG & $17(14.41)$ & $53(18.86)$ & & $0.59(0.31-1.13)$ & 0.109 & $0.57(0.30-1.09)$ & 0.090 \\
\hline Additive & & & 0.179 & $0.75(0.55-1.03)$ & 0.074 & $0.74(0.54-1.01)$ & 0.060 \\
\hline Dominant & $71(60.17)$ & $195(69.40)$ & 0.074 & $0.67(0.43-1.04)$ & 0.075 & $0.65(0.42-1.03)$ & 0.064 \\
\hline Recessive & $101(85.59)$ & $228(81.04)$ & 0.286 & $0.72(0.40-1.31)$ & 0.287 & $0.71(0.39-1.28)$ & 0.253 \\
\hline \multicolumn{8}{|c|}{ rs4758051 $(\mathrm{HWE}=0.946)$} \\
\hline GG & $50(42.37)$ & $88(31.32)$ & & 1.00 & & 1.00 & \\
\hline $\mathrm{AG}$ & $59(50.00)$ & $138(49.11)$ & & $0.75(0.47-1.19)$ & 0.228 & $0.76(0.48-1.21)$ & 0.252 \\
\hline AA & $9(7.63)$ & $55(19.57)$ & & $0.29(0.13-0.63)$ & 0.002 & $0.28(0.13-0.62)$ & 0.002 \\
\hline Additive & & & 0.006 & $0.60(0.43-0.84)$ & 0.003 & $0.60(0.43-0.83)$ & 0.002 \\
\hline Dominant & $68(57.63)$ & $193(68.68)$ & 0.034 & $0.62(0.40-0.97)$ & 0.035 & $0.62(0.40-0.97)$ & 0.035 \\
\hline Recessive & $109(92.37)$ & $226(80.43)$ & 0.003 & $0.34(0.16-0.71)$ & 0.004 & $0.33(0.15-0.69)$ & 0.003 \\
\hline \multicolumn{8}{|c|}{$\mathrm{rs} 10840002(\mathrm{HWE}=0.620)$} \\
\hline $\mathrm{AA}$ & $42(35.59)$ & $78(27.76)$ & & 1.00 & & 1.00 & \\
\hline $\mathrm{AG}$ & $62(52.54)$ & $144(51.25)$ & & $0.80(0.50-1.29)$ & 0.360 & $0.81(0.50-1.31)$ & 0.389 \\
\hline GG & $14(11.86)$ & $59(21.00)$ & & $0.44(0.22-0.88)$ & 0.021 & $0.42(0.21-0.85)$ & 0.016 \\
\hline Additive & & & 0.064 & $0.69(0.50-0.95)$ & 0.025 & $0.68(0.50-0.94)$ & 0.021 \\
\hline Dominant & $76(64.41)$ & $203(72.24)$ & 0.119 & $0.70(0.44-1.10)$ & 0.120 & $0.69(0.44-1.10)$ & 0.119 \\
\hline Recessive & $104(88.14)$ & $222(79.00)$ & 0.031 & $0.51(0.27-0.95)$ & 0.034 & $0.48(0.26-0.91)$ & 0.025 \\
\hline \multicolumn{8}{|c|}{ rs204938 $(\mathrm{HWE}=0.687)$} \\
\hline $\mathrm{AA}$ & $77(65.25)$ & $168(59.79)$ & & 1.00 & & 1.00 & \\
\hline $\mathrm{AG}$ & $36(30.51)$ & $97(34.52)$ & & $0.81(0.51-1.29)$ & 0.377 & $0.82(0.51-1.32)$ & 0.415 \\
\hline GG & $5(4.24)$ & $16(5.69)$ & & $0.68(0.24-1.93)$ & 0.470 & $0.70(0.25-1.98)$ & 0.499 \\
\hline Additive & & & 0.565 & $0.82(0.56-1.19)$ & 0.288 & $0.83(0.57-1.20)$ & 0.323 \\
\hline Dominant & $41(34.75)$ & $113(40.21)$ & 0.306 & $0.79(0.51-1.24)$ & 0.306 & $0.80(0.51-1.26)$ & 0.343 \\
\hline Recessive & $113(95.76)$ & $265(94.31)$ & 0.552 & $0.73(0.26-2.05)$ & 0.554 & $0.74(0.26-2.09)$ & 0.575 \\
\hline
\end{tabular}

${ }^{a} \chi^{2}$ test for genotype distributions between neuroblastoma patients and controls.

${ }^{\mathrm{b}}$ Adjusted for age and gender.

of European ancestry. Thereafter, case-control studies conducted with Italian [24], African-American [25] and Northern Chinese [26] populations verified LMO1 polymorphisms to be factors affecting neuroblastoma risk. In 2016, we conducted the first epidemiological study on the effect of LMO1 polymorphisms on neuroblastoma susceptibility in a Southern Chinese population [22]. We genotyped the aforementioned LMO1 SNPs in 256 cases and 531 controls. We only found that the rs 110419 A $>$ G polymorphism was associated with a significantly lower neuroblastoma risk. However the strength of that conclusion was limited by the small sample. We have therefore now expanded the size of our sample.

Here, we assessed the relationship between $\mathrm{LMOI}$ polymorphisms and neuroblastoma risk in an additional 118 cases and 281 controls. Our analysis indicates that carrying the rs4758051 A or rs $10840002 \mathrm{G}$ allele is associated with decreased risk of neuroblastoma in a
Northern Chinese population. In our earlier study of a Southern Chinese population, we detected a significant protective association between only the rs $110419 \mathrm{~A}>\mathrm{G}$ polymorphism and neuroblastoma risk [22]. Two possible explanations for this discrepancy are as follows. First, the small sizes of the samples used in these two studies means the statistical power of analyzing the association between a single polymorphism and cancer risk is small. Second, because these two studies were conducted in different regions in China, the inconsistency may be attributable to differences in the genetic variations, environmental exposures, and gene-environment interactions across the different regions.

To increase the representation for our conclusions, we combined the results from our present study with those from our earlier one. The combined analysis indicated that carrying the rs $110419 \mathrm{G}$, rs4758051 A or rs $10840002 \mathrm{G}$ allele was associated with a decreased risk 
Table 2: LMO1 polymorphisms and neuroblastoma susceptibility in combined subjects

\begin{tabular}{|c|c|c|c|c|c|c|c|}
\hline Genotype & $\begin{array}{l}\text { Cases } \\
(N=374)\end{array}$ & $\begin{array}{l}\text { Controls } \\
(N=812)\end{array}$ & $P^{a}$ & $\begin{array}{l}\text { Crude OR } \\
(95 \% \text { CI) }\end{array}$ & $\boldsymbol{P}$ & $\begin{array}{l}\text { Adjusted OR } \\
(95 \% \text { CI })^{\mathrm{b}}\end{array}$ & $P^{\mathbf{b}}$ \\
\hline \multicolumn{8}{|c|}{ rs110419 $(\mathrm{HWE}=0.239)$} \\
\hline AA & $150(40.11)$ & $245(30.17)$ & & 1.00 & & 1.00 & \\
\hline $\mathrm{AG}$ & $171(45.72)$ & $417(51.35)$ & & $0.67(0.51-0.88)$ & 0.004 & $0.67(0.51-0.88)$ & 0.004 \\
\hline GG & $53(14.17)$ & $150(18.47)$ & & $0.58(0.40-0.84)$ & 0.004 & $0.58(0.40-0.84)$ & 0.004 \\
\hline Additive & & & 0.003 & $0.74(0.62-0.89)$ & 0.001 & $0.74(0.62-0.89)$ & 0.001 \\
\hline Dominant & $224(59.89)$ & $567(69.83)$ & 0.001 & $0.65(0.50-0.83)$ & 0.001 & $0.65(0.50-0.83)$ & 0.001 \\
\hline Recessive & $321(85.83)$ & $662(81.53)$ & 0.068 & $0.73(0.52-1.02)$ & 0.068 & $0.73(0.52-1.03)$ & 0.069 \\
\hline \multicolumn{8}{|c|}{ rs4758051 $(\mathrm{HWE}=0.271)$} \\
\hline GG & $145(38.77)$ & $282(34.73)$ & & 1.00 & & 1.00 & \\
\hline $\mathrm{AG}$ & $185(49.47)$ & $380(46.80)$ & & $0.95(0.73-1.24)$ & 0.688 & $0.95(0.73-1.24)$ & 0.698 \\
\hline AA & $44(11.76)$ & $150(18.47)$ & & $0.57(0.39-0.84)$ & 0.005 & $0.57(0.39-0.84)$ & 0.005 \\
\hline Additive & & & 0.014 & $0.80(0.67-0.96)$ & 0.014 & $0.80(0.67-0.96)$ & 0.014 \\
\hline Dominant & $229(61.23)$ & $530(65.27)$ & 0.178 & $0.84(0.65-1.08)$ & 0.178 & $0.84(0.65-1.08)$ & 0.182 \\
\hline Recessive & $330(88.24)$ & $662(81.53)$ & 0.004 & $0.59(0.41-0.85)$ & 0.004 & $0.59(0.41-0.84)$ & 0.004 \\
\hline \multicolumn{8}{|c|}{ rs $10840002(\mathrm{HWE}=0.233)$} \\
\hline AA & $132(35.29)$ & $260(32.02)$ & & 1.00 & & 1.00 & \\
\hline $\mathrm{AG}$ & $186(49.73)$ & $384(47.29)$ & & $0.95(0.73-1.25)$ & 0.736 & $0.96(0.73-1.26)$ & 0.744 \\
\hline $\mathrm{GG}$ & $56(14.97)$ & 168 (20.69) & & $0.66(0.46-0.95)$ & 0.025 & $0.66(0.46-0.95)$ & 0.026 \\
\hline Additive & & & 0.062 & $0.83(0.70-0.99)$ & 0.042 & $0.83(0.70-0.99)$ & 0.043 \\
\hline Dominant & $242(64.71)$ & $552(67.98)$ & 0.265 & $0.86(0.67-1.12)$ & 0.266 & $0.87(0.67-1.12)$ & 0.270 \\
\hline Recessive & $318(85.03)$ & $644(79.31)$ & 0.019 & $0.68(0.49-0.94)$ & 0.020 & $0.68(0.49-0.94)$ & 0.020 \\
\hline \multicolumn{8}{|c|}{ rs204938 $(\mathrm{HWE}=0.485)$} \\
\hline $\mathrm{AA}$ & $241(64.44)$ & $522(64.29)$ & & 1.00 & & 1.00 & \\
\hline $\mathrm{AG}$ & $119(31.82)$ & $262(32.27)$ & & $0.98(0.76-1.28)$ & 0.904 & $0.98(0.76-1.28)$ & 0.908 \\
\hline $\mathrm{GG}$ & $14(3.74)$ & $28(3.45)$ & & $1.08(0.56-2.09)$ & 0.813 & $1.07(0.55-2.08)$ & 0.834 \\
\hline Additive & & & 0.961 & $1.01(0.81-1.25)$ & 0.967 & $1.00(0.81-1.25)$ & 0.976 \\
\hline Dominant & $133(35.56)$ & $290(35.71)$ & 0.959 & $0.99(0.77-1.28)$ & 0.959 & $0.99(0.77-1.28)$ & 0.958 \\
\hline Recessive & $360(96.26)$ & $784(96.55)$ & 0.798 & $1.09(0.57-2.09)$ & 0.798 & $1.08(0.56-2.08)$ & 0.820 \\
\hline
\end{tabular}

${ }^{\mathrm{a}} \chi^{2}$ test for genotype distributions between neuroblastoma patients and controls.

${ }^{\mathrm{b}}$ Adjusted for age and gender.

Table 3: False-positive report probability values for significant findings in combined subjects

\begin{tabular}{|c|c|c|c|c|c|c|c|c|}
\hline \multirow{2}{*}{ Genotype } & \multirow{2}{*}{$\begin{array}{l}\text { Crude OR } \\
(95 \% \text { CI) }\end{array}$} & \multirow{2}{*}{$P^{\mathrm{a}}$} & \multirow{2}{*}{$\begin{array}{l}\text { Statistical } \\
\text { Power }^{\text {b }}\end{array}$} & \multicolumn{5}{|c|}{ Prior probability } \\
\hline & & & & 0.25 & 0.1 & 0.01 & 0.001 & 0.0001 \\
\hline \multicolumn{9}{|l|}{$\mathrm{rs} 110419 \mathrm{~A}>\mathrm{G}$} \\
\hline AG vs. AA & $0.67(0.51-0.88)$ & 0.004 & 0.606 & 0.017 & 0.051 & 0.370 & 0.856 & 0.983 \\
\hline GG vs. AA & $0.58(0.40-0.84)$ & 0.004 & 0.256 & 0.044 & 0.120 & 0.601 & 0.938 & 0.993 \\
\hline AG/GG vs. AA & $0.65(0.50-0.83)$ & 0.001 & 0.392 & 0.006 & 0.018 & 0.168 & 0.671 & 0.953 \\
\hline \multicolumn{9}{|l|}{$\mathrm{rs} 4758051 \mathrm{G}>\mathrm{A}$} \\
\hline AA vs. GG & $0.57(0.39-0.84)$ & 0.005 & 0.284 & 0.050 & 0.137 & 0.635 & 0.946 & 0.994 \\
\hline AA vs. GG/AG & $0.59(0.41-0.85)$ & 0.004 & 0.259 & 0.044 & 0.122 & 0.605 & 0.939 & 0.994 \\
\hline \multicolumn{9}{|l|}{ rs $10840002 \mathrm{~A}>\mathrm{G}$} \\
\hline GG vs. AA & $0.66(0.46-0.95)$ & 0.025 & 0.557 & 0.119 & 0.288 & 0.816 & 0.978 & 0.998 \\
\hline GG vs. AG/AA & $0.68(0.49-0.94)$ & 0.020 & 0.521 & 0.103 & 0.257 & 0.792 & 0.975 & 0.997 \\
\hline
\end{tabular}

${ }^{a}$ Chi-square test was used to calculate the genotype frequency distributions.

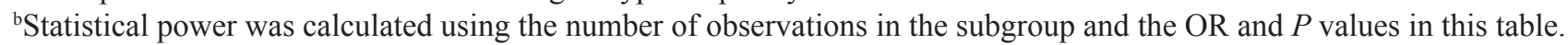


for neuroblastoma. The larger sample in the combined analysis highlights the important protective effect of LMO1 polymorphisms on neuroblastoma risk. In addition, the FPRP analysis also enhances the robustness of our findings.

Although this is a relatively large sample for investigating the correlation between $L M O 1$ polymorphisms and neuroblastoma risk in the Chinese, several limitations still exist. First, we only genotyped four SNPs in this study, other potentially functional polymorphisms not discovered in genome-wide association studies were omitted. These include the rs2168101 $\mathrm{G}>\mathrm{T}$ polymorphism, which was recently found to be associated with neuroblastoma [14]. Second, all of the subjects were recruited from two hospitals and most lived in Southern or Northern China, which inevitably caused selection bias. Third, we failed to assess several important environmental factors, including dietary intake, paternal exposures, and the subjects' living environment. The absence of such information limits our ability to conduct a gene-environmental interaction analysis. Fourth, the sample size is still not large enough to ensure a robust conclusion. Fifth, the potential mechanisms of action of the four polymorphisms were not studied. Experimental analysis of the mechanisms of potentially functional $L M O 1$ polymorphisms is needed.

In summary, we have further confirmed the protective effect of LMO1 polymorphisms on neuroblastoma susceptibility in a Chinese population. More casecontrol studies based on other ethnicities and multicenter investigations are encouraged to support these observations.

\section{MATERIALS AND METHODS}

\section{Study subjects}

The recruitment criteria for neuroblastoma patients and controls were described previously [22, 27, 28]. A total of 118 neuroblastoma patients and 281 healthy controls from Henan province (Northern China) were ultimately included in the study [29]. Briefly, all children with neuroblastoma histologically confirmed at The First Affiliated Hospital of Zhengzhou University between August 2011 and April 2017 were enrolled in the study. During the same period, 281 age- and gender-matched controls were also recruited at the same hospital. Before their participation, we obtained informed written consent for all subjects. The present study was approved by the Institutional Review Board of the hospital.

\section{SNP selection and genotyping}

Four LMO1 SNPs (rs110419 A > G, rs4758051 G > A, rs10840002 A $>$ G and rs204938 A $>$ G) identified as being associated with neuroblastoma in an earlier genome-wide association study were selected (Supplementary Table 2) [16]. Genotyping these four SNPs was performed using Taqman real-time PCR. The detailed procedure can be found in our earlier study [30]. To ensure the accuracy of the genotyping results, about $10 \%$ of the samples were also genotyped by sequencing [31, 32], and 100\% genotype concordance was obtained.

\section{Statistical analysis}

The goodness-of-fit $\chi^{2}$ test was applied to assess whether the selected SNPs were in Hardy-Weinberg equilibrium among the controls. Two-sided $\chi^{2}$ tests were employed to compare demographic variables and genotype frequencies between cases and controls. To evaluate the strength of the relationship between LMO1 polymorphisms and neuroblastoma susceptibility, ORs and $95 \%$ CIs were calculated using unconditional logistic regression analyses. To determine whether the significant findings were "noteworthy", we adopted the FPRP analysis $[33,34]$. We calculated FPRP for a range of prior probabilities from 0.0001 to 0.25 and used 0.2 as a cut-point for FPRP. Values of $P<0.05$ were considered statistically significant. SAS software (version 9.4; SAS Institute, Cary, NC) was used to perform all statistical analyses.

\section{ACKNOWLEDGMENTS AND FUNDING}

This study was supported by grants from National Natural Science Foundation of China (No. 81502187), Pearl River S\&T Nova Program of Guangzhou (No: 201710010086), and State Clinical Key Specialty Construction Project (Pediatric Surgery) 2013 (No: GJLCZD1301).

\section{CONFLICTS OF INTEREST}

No competing interests to declare.

\section{REFERENCES}

1. Maris JM, Hogarty MD, Bagatell R, Cohn SL. Neuroblastoma. Lancet. 2007; 369:2106-2120.

2. Smith MA, Seibel NL, Altekruse SF, Ries LA, Melbert DL, O'Leary M, Smith FO, Reaman GH. Outcomes for children and adolescents with cancer: challenges for the twenty-first century. J Clin Oncol. 2010; 28:2625-2634.

3. Bao PP, Li K, Wu CX, Huang ZZ, Wang CF, Xiang YM, Peng P, Gong YM, Xiao XM, Zheng Y. [Recent incidences and trends of childhood malignant solid tumors in Shanghai, 2002-2010]. [Article in Chinese]. Zhonghua Er Ke Za Zhi. 2013; 51:288-294.

4. Matthay KK, Villablanca JG, Seeger RC, Stram DO, Harris RE, Ramsay NK, Swift P, Shimada H, Black CT, Brodeur GM, Gerbing RB, Reynolds CP. Treatment of high-risk neuroblastoma with intensive chemotherapy, radiotherapy, autologous bone marrow transplantation, and 
13-cis-retinoic acid. Children's Cancer Group. N Engl J Med. 1999; 341:1165-1173.

5. Laverdiere C, Liu Q, Yasui Y, Nathan PC, Gurney JG, Stovall M, Diller LR, Cheung NK, Wolden S, Robison LL, Sklar CA. Long-term outcomes in survivors of neuroblastoma: a report from the Childhood Cancer Survivor Study. J Natl Cancer Inst. 2009; 101:1131-1140.

6. Kaatsch P. Epidemiology of childhood cancer. Cancer Treat Rev. 2010; 36:277-285.

7. Maris JM. Recent advances in neuroblastoma. N Engl J Med. 2010; 362:2202-2211.

8. De Roos AJ, Olshan AF, Teschke K, Poole C, Savitz DA, Blatt J, Bondy ML, Pollock BH. Parental occupational exposures to chemicals and incidence of neuroblastoma in offspring. Am J Epidemiol. 2001; 154:106-114.

9. De Roos AJ, Teschke K, Savitz DA, Poole C, Grufferman S, Pollock BH, Olshan AF. Parental occupational exposures to electromagnetic fields and radiation and the incidence of neuroblastoma in offspring. Epidemiology. 2001; 12:508-517.

10. Patton T, Olshan AF, Neglia JP, Castleberry RP, Smith J. Parental exposure to medical radiation and neuroblastoma in offspring. Paediatr Perinat Epidemiol. 2004; 18:178-185.

11. Capasso M, Diskin SJ. Genetics and genomics of neuroblastoma. Cancer Treat Res. 2010; 155:65-84.

12. Han W, Zhou Y, Zhong R, Wu C, Song R, Liu L, Zou L, Qiao Y, Zhai K, Chang J, Huang L, Lu X, Lou J, et al. Functional polymorphisms in FAS/FASL system increase the risk of neuroblastoma in Chinese population. PLoS One. 2013; 8:e71656.

13. Capasso M, Diskin S, Cimmino F, Acierno G, Totaro F, Petrosino G, Pezone L, Diamond M, McDaniel L, Hakonarson H, Iolascon A, Devoto M, Maris JM. Common genetic variants in NEFL influence gene expression and neuroblastoma risk. Cancer Res. 2014; 74:6913-6924.

14. Oldridge DA, Wood AC, Weichert-Leahey N, Crimmins I, Sussman R, Winter C, McDaniel LD, Diamond M, Hart LS, Zhu S, Durbin AD, Abraham BJ, Anders L, et al. Genetic predisposition to neuroblastoma mediated by a LMO1 super-enhancer polymorphism. Nature. 2015; 528:418-421.

15. He J, Wang F, Zhu J, Zhang R, Yang T, Zou Y, Xia H. Association of potentially functional variants in the XPG gene with neuroblastoma risk in a Chinese population. J Cell Mol Med. 2016; 20:1481-1490.

16. Wang K, Diskin SJ, Zhang H, Attiyeh EF, Winter C, Hou C, Schnepp RW, Diamond M, Bosse K, Mayes PA, Glessner J, Kim C, Frackelton E, et al. Integrative genomics identifies LMO1 as a neuroblastoma oncogene. Nature. 2011; 469:216-220.

17. Boehm T, Foroni L, Kennedy M, Rabbitts TH. The rhombotin gene belongs to a class of transcriptional regulators with a potential novel protein dimerisation motif. Oncogene. 1990; 5:1103-1105.

18. Matthews JM, Lester K, Joseph S, Curtis DJ. LIM-domainonly proteins in cancer. Nat Rev Cancer. 2013; 13:111-122.
19. Greenberg JM, Boehm T, Sofroniew MV, Keynes RJ, Barton SC, Norris ML, Surani MA, Spillantini MG, Rabbitts TH. Segmental and developmental regulation of a presumptive T-cell oncogene in the central nervous system. Nature. 1990; 344:158-160.

20. Boehm T, Baer R, Lavenir I, Forster A, Waters JJ, Nacheva E, Rabbitts TH. The mechanism of chromosomal translocation $\mathrm{t}(11 ; 14)$ involving the $\mathrm{T}$-cell receptor $\mathrm{C}$ delta locus on human chromosome 14q11 and a transcribed region of chromosome 11p15. EMBO J. 1988; 7:385-394.

21. Beuten J, Gelfond JA, Piwkham D, Pollock BH, Winick NJ, Collier AB 3rd, Tomlinson GE. Candidate gene association analysis of acute lymphoblastic leukemia identifies new susceptibility locus at $11 \mathrm{p} 15$ (LMO1). Carcinogenesis. 2011; 32:1349-1353.

22. He J, Zhong W, Zeng J, Zhu J, Zhang R, Wang F, Yang T, Zou Y, Xia H. LMO1 gene polymorphisms contribute to decreased neuroblastoma susceptibility in a Southern Chinese population. Oncotarget. 2016; 7:22770-22778. https://doi.org/10.18632/oncotarget.8178.

23. Brodeur GM, Pritchard J, Berthold F, Carlsen NL, Castel V, Castelberry RP, De Bernardi B, Evans AE, Favrot M, Hedborg F. Revisions of the international criteria for neuroblastoma diagnosis, staging and response to treatment. Prog Clin Biol Res. 1994; 385:363-369.

24. Capasso M, Diskin SJ, Totaro F, Longo L, De Mariano M, Russo R, Cimmino F, Hakonarson H, Tonini GP, Devoto M, Maris JM, Iolascon A. Replication of GWAS-identified neuroblastoma risk loci strengthens the role of BARD1 and affirms the cumulative effect of genetic variations on disease susceptibility. Carcinogenesis. 2013; 34:605-611.

25. Latorre V, Diskin SJ, Diamond MA, Zhang H, Hakonarson H, Maris JM, Devoto M. Replication of neuroblastoma SNP association at the BARD1 locus in African-Americans. Cancer Epidemiol Biomarkers Prev. 2012; 21:658-663.

26. Lu J, Chu P, Wang H, Jin Y, Han S, Han W, Tai J, Guo Y, Ni X. Candidate Gene Association Analysis of Neuroblastoma in Chinese Children Strengthens the Role of LMO1. PLoS One. 2015; 10:e0127856.

27. He J, Zhang R, Zou Y, Zhu J, Yang T, Wang F, Xia H. Evaluation of GWAS-identified SNPs at $6 \mathrm{p} 22$ with neuroblastoma susceptibility in a Chinese population. Tumour Biol. 2016; 37:1635-1639.

28. He J, Wang F, Zhu J, Zhang Z, Zou Y, Zhang R, Yang T, Xia H. The TP53 gene rs1042522 C > G polymorphism and neuroblastoma risk in Chinese children. Aging (Albany NY). 2017; 9:852-859. https://doi.org/10.18632/ aging. 101196.

29. Zhang J, Wang J, Liu Q, Gao J, Wang Q. Polymorphisms of glucose-regulated protein 78 and clinical relevance of neuroblastoma: Risk and prognosis. J Cancer Res Ther. $2016 ; 12: 1178-1183$.

30. He J, Qiu LX, Wang MY, Hua RX, Zhang RX, Yu HP, Wang YN, Sun MH, Zhou XY, Yang YJ, Wang JC, Jin L, 
Wei QY, et al. Polymorphisms in the XPG gene and risk of gastric cancer in Chinese populations. Hum Genet. 2012; 131:1235-1244.

31. Li J, Zou L, Zhou Y, Li L, Zhu Y, Yang Y, Gong Y, Lou J, Ke J, Zhang Y, Tian J, Zou D, Peng X, et al. A low-frequency variant in SMAD7 modulates TGF-beta signaling and confers risk for colorectal cancer in Chinese population. Mol Carcinog. 2017; 56:1798-1807.

32. Lou J, Gong J, Ke J, Tian J, Zhang Y, Li J, Yang Y, Zhu Y, Gong Y, Li L, Chang J, Zhong R, Miao X. A functional polymorphism located at transcription factor binding sites, rs6695837 near LAMC1 gene, confers risk of colorectal cancer in Chinese populations. Carcinogenesis. 2017; 38:177-183.
33. Wacholder S, Chanock S, Garcia-Closas M, El Ghormli L, Rothman N. Assessing the probability that a positive report is false: an approach for molecular epidemiology studies. J Natl Cancer Inst. 2004; 96:434-442.

34. He J, Wang MY, Qiu LX, Zhu ML, Shi TY, Zhou XY, Sun MH, Yang YJ, Wang JC, Jin L, Wang YN, Li J, Yu HP, et al. Genetic variations of mTORC1 genes and risk of gastric cancer in an Eastern Chinese population. Mol Carcinog. 2013; 52:E70-79. 